\title{
Prediction of Ventilation Effects on Reducing Moisture Damage in Tishun Tang in the Palace Museum in Beijing, China
}

\author{
Yan $\mathrm{Ma}^{1}$, Yonghui $\mathrm{Li}^{1{ }^{1,},}$, Shuichi Hokoi ${ }^{1}$, and Xiaogu Zhang ${ }^{2}$ \\ ${ }^{1}$ School of Architecture, Southeast University, 210096 Nanjing, China \\ ${ }^{2}$ Department of Architectural heritage, the Palace Museum, 100009 Beijing, China
}

\begin{abstract}
The Palace Museum in Beijing is World Cultural Heritage and representative of Chinese traditional brick buildings, but has been suffering deterioration for centuries. Environment monitoring showed that the special construction of foundation resulted in the humid micro-environment and moisture damage near wall bottom and floor in buildings. In order to make clear the effects of ventilation on reducing moisture damage, we took Tishun Tang as example and built a two-dimensional hygrothermal simulation model. There are two ventilation plans. One is direct ventilation, letting the outdoor air go into indoor space directly through the flue under floor. The other is to add air temperature and humidity control during that produce, called controlled ventilation. In those two plans, ventilation rate is raised to 1 time per hour from 0.4 times (current state). The results show that compared with direct ventilation, controlled ventilation is more efficient for reducing moisture damage. In controlled ventilation plan, heating outdoor air before the air exchange in winter benefits to raising indoor surface temperature by one degree and reducing area of freezing-thawing damage. Dehumidifying the outdoor air during ventilation in summer is the most important point of decreasing the high mould risk from $22 \sim 25$ days to $7 \sim 10$ days.
\end{abstract}

\section{Background}

The Palace Museum in Beijing built in 15th century, with outstanding historical and aesthetic value, is world cultural heritage and the representative of Chinese traditional buildings. But now heritage buildings in the Palace Museum have been suffering serious deterioration for decades, such as condensation on the surface of wall, and damping of indoor floor, as shown in figure 1. The heritage building in the Palace Museum, including other Chinese traditional building, are constructed by blue bricks. Blue brick is an important traditional construction material in China with a long history of manufacturing and a wide range of uses. Meanwhile, blue brick is a kind of porous material with hygroscopic sorption and permeability properties [1]. Water/moisture can go through it freely [2], which easily leads to condensation in porous material, damping, and microbial deterioration [3]. Other moisture damage incudes peeling, exfoliation, salt deposition, freezing-thawing cycling, or dryingwetting cycling $[4,5]$ and so on, and any of them can destroy the significant value of heritage buildings. Therefore, one of the urgent issues of building heritage conservation is to reduce moisture damage.

For the purpose of long-term conservation of building heritage, environment control is a future-oriented way of reducing deterioration, and how to carry it out usually depends on the current state of the object. In previous investigation, archaeologists and conservators found some channels under the floor of heritage buildings in the Palace Museum, as shown in figure 2. They deduced that these channels were flue that is a kind of common heating facilities of Chinese traditional buildings. But now most of these facilities in the Palace Museum have been completely abandoned. The entrance and exit were blocked by dust and then air cannot go through very well, as shown in figure 2(a). Because of that, the air in the flue space is always humid, which is highly related to damping, salting-out, and other moisture damage in these buildings [6]. If the flue was repaired and the entrance was added to the indoor room, these channels can be used for ventilation, as shown in figure 2(b). That not only supplies a good solution of carrying out environment control, but also does not change the original state of heritage buildings a lot [6].

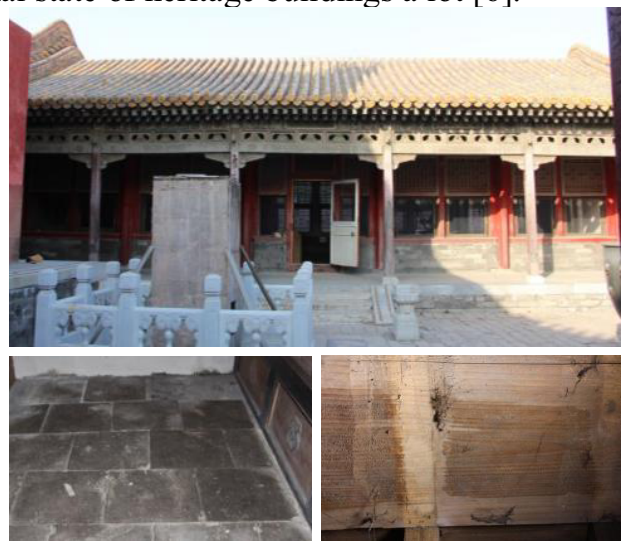

Fig. 1. South façade of Tishun Tang, and moisture damage in it (damping on floor, and condensation on wooden board)

\footnotetext{
* Corresponding author: liyonghui@seu.edu.cn
} 
In this paper, we focus on moisture transfer and accumulation on brick masonry, mainly on floor and walls, which significantly affects the damping and other moisture damage in the heritage buildings of the Palace Museum. We investigated the current conditions of the buildings, and inferred the possible source of moisture by environment monitoring. After that, we take Tishun Tang, one typical building in the Palace Museum, as the example. We built a hygrothermal model to calculate the temperature and moisture distribution on Tishun Tang. Through the simulation by this model we can make clear the effects of ventilation on reducing moisture damage.

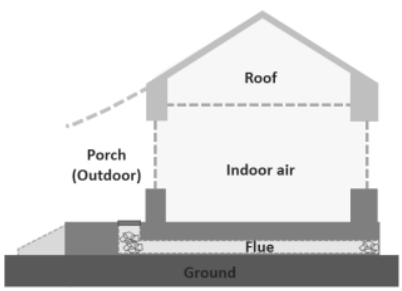

(a)

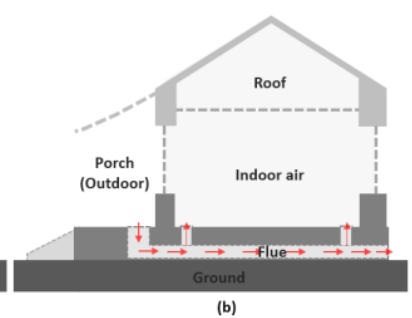

(b)
Fig. 2. Diagram of the flue under floor of Tishun Tang: (a) before repair; (b) design for ventilation

\section{Methodology}

\subsection{Environment monitoring}

Tishun Tang is one of the main buildings in Yangxin Dian building group which is located in the west of the Palace Museum. It faces south and has a gable roof. It is a one-story building and 8.2 meters wide from north to south (including a 2.5-meter wide porch on the south side), 16.2 meters long from east to west, and 6.0 meters high. All of the buildings in Yangxin Dian have been closed to the public for research and conservation since December of the year 2015.

In the year 2018, we conducted deterioration survey in different buildings of Yangxin Dian, and especially the environment monitoring in Tishun Tang. As shown in figure 3, the 6-meter deep hole is for ground temperature and water content monitoring. We put five $\mathrm{ECH}_{2} \mathrm{O} 5 \mathrm{TE}$ probes (METER, USA) in the hole, starting one meter underground and spacing one meter apart each other. The outdoor and indoor temperature and relative humidity $(\mathrm{RH})$ was measured by auto-recorders (Kimo, $\mathrm{CHN}$ ) whose measurement range are $0 \sim 100 \% \mathrm{RH}$ and $40 \sim 125{ }^{\circ} \mathrm{C}$ with accuracy of $\pm 3 \% \mathrm{RH}, \pm 0.5{ }^{\circ} \mathrm{C}$. The two indoor measure points were at corner and centre respectively of the second room on the east side of Tishun Tang, and the outdoor point was in the porch outside this room with height of three meters. There is a wooden bed on the south side in this room (figure 3). In the field survey, we found the floor at corner and under bed was wetter, and sometimes mould growth occurred, so we set Point-T\&RH 2 to show the humid environment there. Point-T\&RH 1 at room centre was chose to represent the average temperature and $\mathrm{RH}$ conditions of building. Surface temperature of floor was also measured by thermal couple at Point-T 1 for model check.

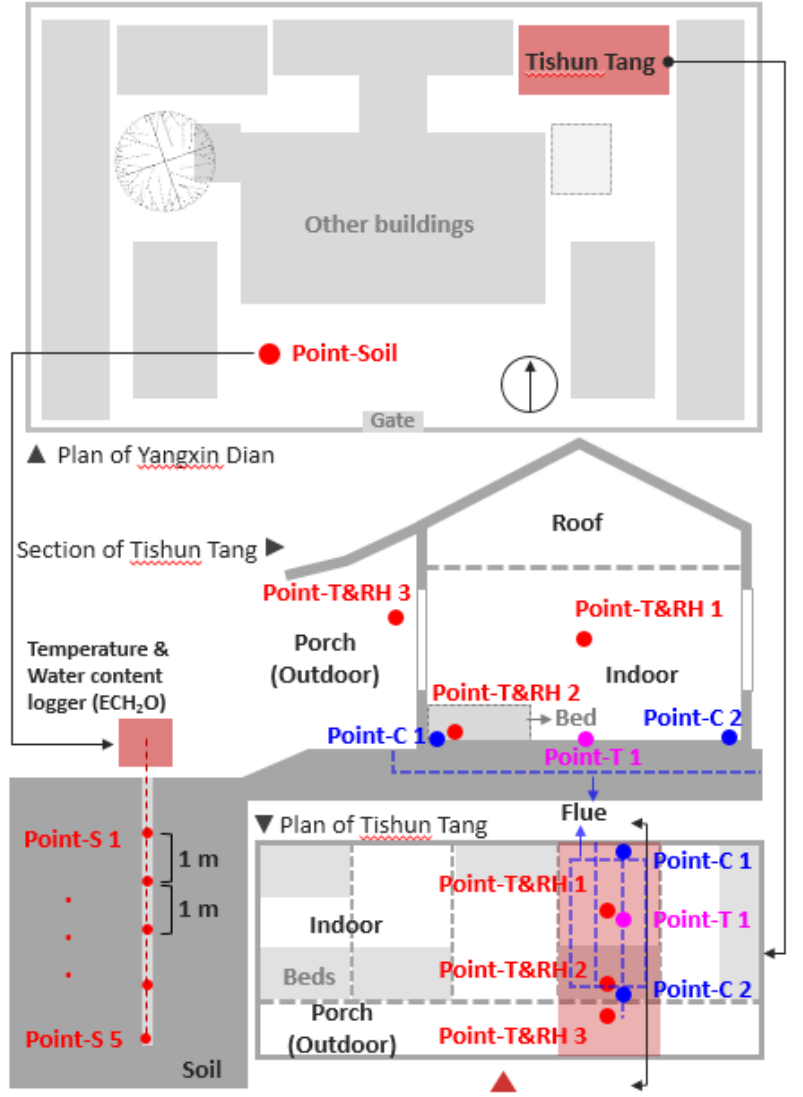

Fig. 3. Diagram of environment monitoring of Tishun Tang (Point-S 1 5 are soil temperature and water content measure points; Point-T\&RH 1 3 are air temperature and RH measure points; Point-T 1 is surface temperature measure point, Point-C 1 and $\mathrm{C} 2$ are for numerical model analysis.)

\subsection{Fundamental equations of heat and moisture coupled transfer}

We built a two-dimensional numerical model of the Tishun Tang building in accordance with the actual scale. In this model, simulation of heat and moisture transfer in porous materials was performed by equation (1) and (2) [7], which was built in 1978 by Matsumoto and has been successfully applied in previous research $[8,9]$ :

Heat balance:

$$
c \rho \partial T / \partial t=\partial / \partial x\left[\partial T / \partial x\left(\lambda+r \lambda^{\prime}{ }_{\mathrm{Tg}}\right)+r \lambda^{\prime}{ }_{\mu \mathrm{g}}\left(\partial \mu / \partial x-\mathrm{n}_{\mathrm{x}} g\right)\right]
$$

Moisture balance:

$$
\begin{gathered}
\rho_{w} \partial \Psi / \partial t=\partial / \partial x\left[\partial T / \partial x \lambda_{\mathrm{T}}^{\prime}+\lambda_{\mu}^{\prime}\left(\partial \mu / \partial x-\mathrm{n}_{\mathrm{x}} g\right)\right] \\
\mu=R_{v} \cdot T \cdot \ln (R H)
\end{gathered}
$$

Where, c, $\rho, \rho_{\mathrm{w}}, \Psi$ respectively refer to thermal capacity, density, water density and volumetric moisture content. $\mathrm{T}$ is temperature; $\mathrm{RH}$ is relative humidity; $\mu$ is water chemical potential, which shows the degree of wetness and is related to $\mathrm{T}$ and $\mathrm{RH}$, as shown in equation (3). The wetter material is, the larger $\mu$ value (less than zero) is. $\mathrm{R}_{\mathrm{v}}$ is gas constant of water vapor; $\lambda$ is thermal conductivity; $\lambda^{\prime}{ }_{\mathrm{T}}$ and $\lambda^{\prime}{ }_{\mu}$ are water conductivity driven by temperature and water chemical potential respectively; 
$\lambda^{\prime}{ }_{\mathrm{Tg}}$ and $\lambda^{\prime}{ }_{\mu \mathrm{g}}$ are water vapor conductivity related to temperature and water chemical potential respectively; $r$ is phase change heat for vaporization; $t$ is time, and $g$ is gravity acceleration; $\mathrm{n}_{\mathrm{x}}$ is the vector to show direction of heat and moisture transfer. If they transfer upwards along vertical direction, $\mathrm{n}_{\mathrm{x}}$ is 1 , and downwards is -1 . If they transfer along horizonal direction, $\mathrm{n}_{\mathrm{x}}$ is 0 .

\subsection{Boundary conditions}

In the two dimensional numerical model of Tishun Tang, the third kind of boundary condition was applied to the outer and inner surfaces. The outdoor temperature and RH were measured every 30 minutes by the weather station in the Palace Museum for a whole year. Also the whole-year precipitation and solar radiation data were measured. The indoor room was divided into up and down parts by ceiling, and there is air exchange between the two parts. The temperature and $\mathrm{RH}$ of those two parts were both calculated as one zone based on the outdoor weather conditions and hygrothermal properties of building envelops. According to the results of geological examination by department of Architectural Heritage of the Palace Museum, the shallow ground water is about 2.3 meters underground, so we set the soil at 2.3 meters underground water saturated ( $\mu$ equals -5 $\mathrm{J} / \mathrm{kg}$ ). The temperature of this layer was measured. Left and right sides of the ground were calculated as infinite boundary, that is the boundary of heat and moisture insulation. Other details about finite element mesh dividing, material properties in this model were explained in our previous paper [10].

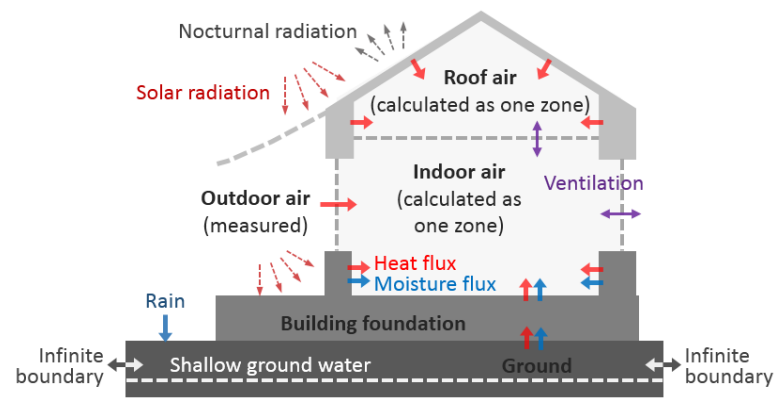

Fig. 4. Boundary conditions of the Tishun Tang hygrothermal simulation model

\subsection{Ventilation design}

We designed two plans of ventilation through the flue, and the effects of reducing moisture damage of the two cases will be discussed following. In our model, the ventilation rate of current state is 0.4 times per hour $[/ \mathrm{h}]$. The first plan (Case 1) is natural ventilation, that is we clear the entrance and exit of the flue, and let the outdoor air exchange with indoor air directly. The second plan (Case 2) is controlled ventilation. We assumed that heating the indoor room in winter and cooling and dehumidifying in summer can strengthen the effects of ventilation on moisture damage reducing. Therefore, we kept temperature of the air going into room at $4 \sim 20^{\circ} \mathrm{C}$, and $\mathrm{RH}$ lower than $50 \%$, as shown in figure 5. Limited by power supply in the Palace Museum, ventilation of Case 2 only works from 8:00 a.m. to 17:00 p.m.. Ventilation rate in both two plans were increased to $1 / \mathrm{h}$.

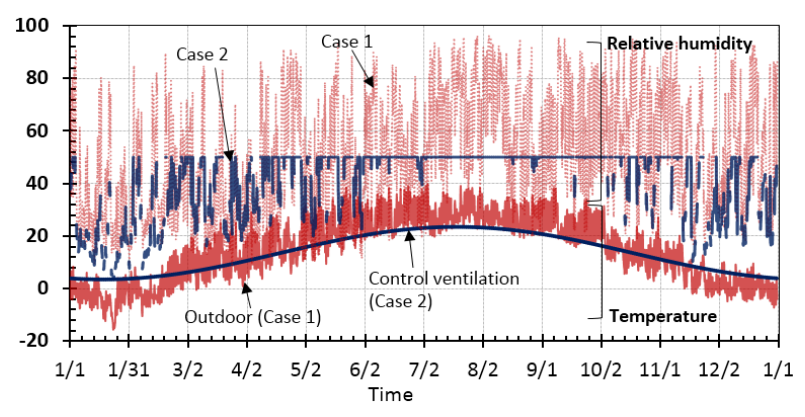

Fig. 5. Temperature and RH of the air ventilated into Tishun Tang in Case 1 and Case 2

\section{Results and discussion}

\subsection{Hygrothermal conditions of the ground and indoor space}

According to the monitoring results at different depths underground in figure 6 , the seasonal variations in ground temperature and water content can be seen obviously. Ground temperature reached their top in July and August, and dropped to the bottom in February. The average temperature of ground within these five meters were $16.4 \sim 16.9{ }^{\circ} \mathrm{C}$. The difference of ground temperature from winter to summer increased with the decrease of the depth. At one meter underground, whose annual difference was the largest, the minimum temperature was $3.5^{\circ} \mathrm{C}$ and the maximum was $27.2{ }^{\circ} \mathrm{C}$. The ground temperature at five meters deep had the narrowest annual difference (only three degrees).

Totally different with temperature, ground water content raised up suddenly in rainy season, that are June, July and August. Except for the rainy season, ground water content gradually increased from one meter to four meters underground. Ground at three and four meters had the highest water content with values of $0.18 \mathrm{~m}^{3} / \mathrm{m}^{3}$. It should be noted that water content at five meters underground was very low with the value no more than $0.002 \mathrm{~m}^{3} / \mathrm{m}^{3}$. During the rain, the increment of ground water content also increased with the decrease of the depth. The ground water content at one and two meters deep reached the saturation in a short time from 0.003 $\mathrm{m}^{3} / \mathrm{m}^{3}$, and it at three meters doubled and increased to about $0.4 \mathrm{~m}^{3} / \mathrm{m}^{3}$, but water content at four and five meters were almost constant, as shown in figure 6 .

According to the distribution of ground water content and the result of shallow ground water in geological examination, it can be deduced that rainwater infiltrated very quickly in the soil at one and two meters underground, but most of them was blocked at a layer between two and three meters, whose water permeability coefficient was very small. Previous study also showed that the foundation of buildings in the Palace Museum was constructed specially [11]. The top $2 \sim 3$ meters of foundation is an artificial earthen layer. This layer 
usually made by several layers of earthen rubble or earthen soil, and the top surface is brickwork. Therefore, not only the shallow ground water at 2.3 meters but also the low-permeability ground layer were took into account in the numerical model of Tishun Tang.
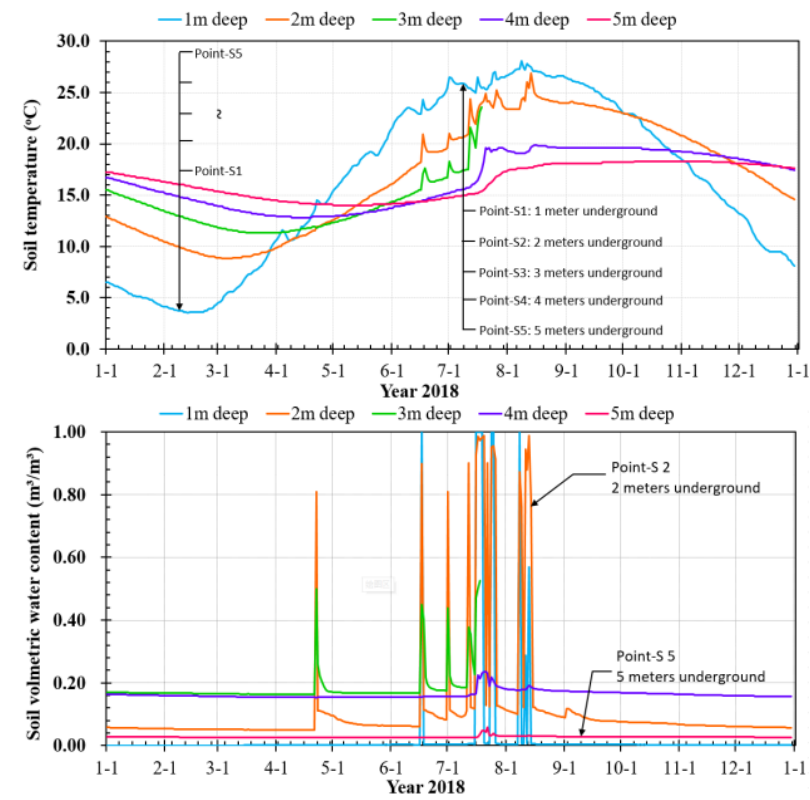

Fig. 6. Measured temperature and water content of ground

Figure 7 shows the measured results of indoor air temperature and $\mathrm{RH}$. The air temperature at corner was 0 $\sim 5^{\circ} \mathrm{C}$ in winter, and $26 \sim 30{ }^{\circ} \mathrm{C}$ in summer. At room centre, air temperature was $-4 \sim 4{ }^{\circ} \mathrm{C}$ in winter, and $27 \sim$ $34{ }^{\circ} \mathrm{C}$ in summer. The temperature at indoor corner was two degrees higher in winter, and three degrees lower in summer than the room average temperature (temperature at room centre was took as the room average temperature). Furthermore, the amplitude of indoor air temperature was $2 \sim 5$ degrees smaller than outdoor air. $\mathrm{RH}$ at corner and at room centre were almost the same in winter with values of $22 \% \sim 48 \%$. But most of time in summer, $\mathrm{RH}$ at corner is $10 \%$ higher than room centre. Humidity ratio was also calculated, showing that air near corner had higher humidity ratio than room centre, and the largest difference is about $4 \mathrm{~g} / \mathrm{kg}$ in August.

According to the indoor temperature and humidity ratio, it can be seen that more moisture gathering at room corner, which leads to higher risk of moisture deterioration. For example, we found mould growth and condensation on the floor, as well as wet wall paper and wooden board near room corners.
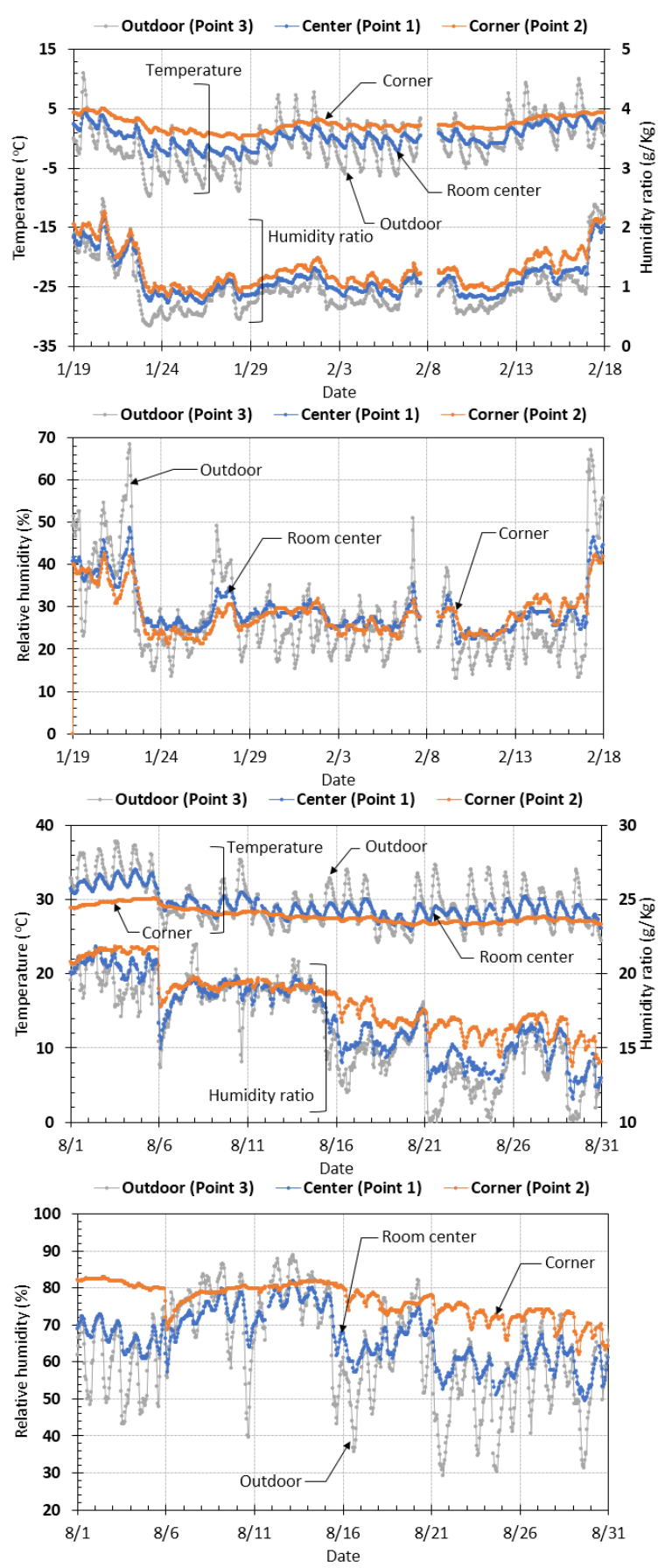

Fig. 7. Measured results of indoor air temperature and humidity of Tishun Tang in winter (January to February) and summer (August)

Combined that with previous results of ground water content, it is indicated that most of the moisture at corner comes from shallow ground water. The rainwater is stopped by low-permeability ground layer, then they are transferred into indoor floor and wall bottom, and finally evaporated into indoor room. That is why indoor floor and wall bottom of the heritage buildings in the Palace Museum commonly found damp, and it also the main reason of humid indoor environment of the one-story buildings like Tishun Tang. Many buildings have the wooden beds against the outer wall, which aggravates the damp of the wall bottom and floor below the beds. 


\subsection{Model check}

Figure 8 shows the comparison of the measured and simulated values. The calculated indoor temperature is $6.0 \sim 31.6{ }^{\circ} \mathrm{C}$, and the average value is $15.6{ }^{\circ} \mathrm{C}$. The calculated air $\mathrm{RH}$ is $13.3 \% \sim 86.1 \%$, and average value is $40.4 \%$. Before August, the calculated temperature and relative humidity is consistent well with the measured value of room centre, except for that the amplitude of the calculated data is a little larger. That may be due to the numerical model we built is two-dimensional. From August to October, the calculated temperature is about two degrees higher than the measured value, and correspondingly, the calculated $\mathrm{RH}$ is $5 \%$ lower than the measured value. It is because that during that time, the tiles and mortar of roof were removed for repair and the insulation property of the roof became weak.

We also compared the calculated surface temperature with measured value at floor centre (Point-T 1), as in figure 8(c). Even only intermittent data we have, the calculated temperature is in good agreement with those measured values. Therefore, the numerical model conforms to the real situation well.
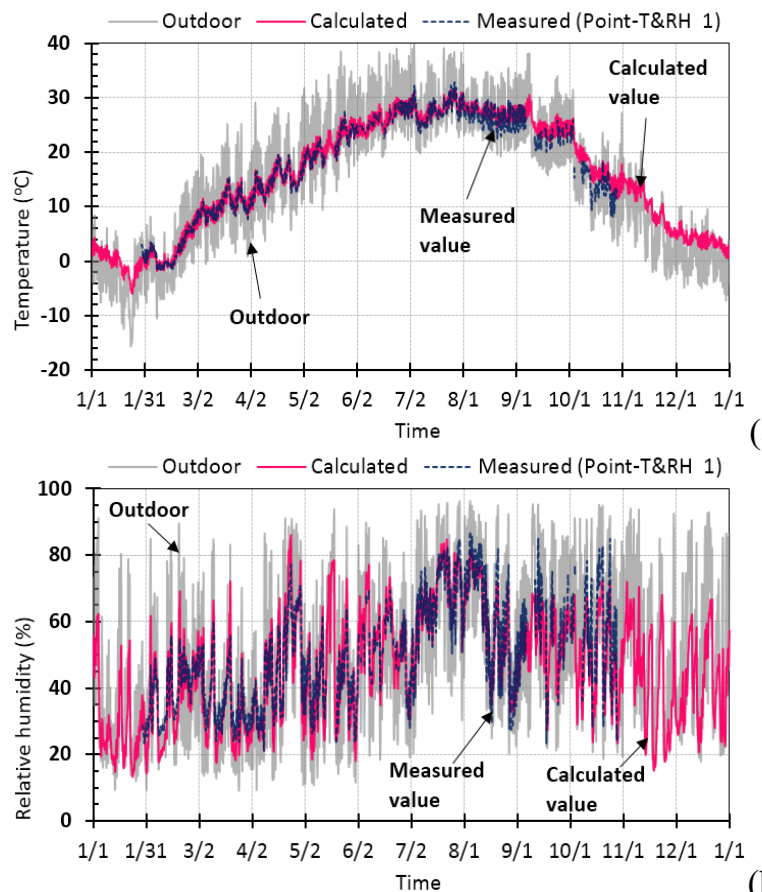

(b)

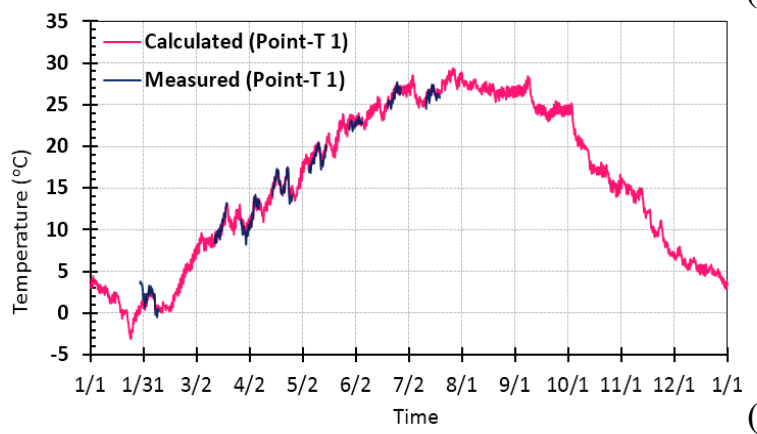

(c)

Fig. 8. comparison of the measured and simulated reaults of TIshun Tang: (a) indoor air temperature; (b) indoor air RH; (c) floor surface temperature

\subsection{Building temperature and moisture content after ventilation}

Based on the validated numerical model of Tishun Tang, we simulated the hygrothermal performance of Tishun Tang in the two designed ventilation plans. In case 1 of direct ventilation, the indoor air temperature is $-7.8 \sim$ $32.6{ }^{\circ} \mathrm{C}$ with average value of $15.4{ }^{\circ} \mathrm{C}$, and $\mathrm{RH}$ is $11.3 \%$ $\sim 85.3 \%$ with average value of $46.4 \%$. If we control the temperature and $\mathrm{RH}$ of the air ventilated into the building in case 2 , indoor air temperature becomes -5.4 $\sim 30.4{ }^{\circ} \mathrm{C}$ with average value of $15.3{ }^{\circ} \mathrm{C}$, and indoor $\mathrm{RH}$ is $11.6 \% \sim 84.3 \%$ with average value of $45.1 \%$.

As figure 9 shows, the indoor floor surface has the smaller temperature fluctuations than walls, that is floor surface temperature is higher than walls in winter, and lower in summer. The situation of moisture content is opposite. In case 1 , the indoor surface temperature is decreased 1.6 degrees in the coldest day and increased 0.5 degrees in the hottest day. The control ventilation in case 2 can raise the surface temperature by 0.9 degree in winter and reduce it by 1.0 degrees in summer. For moisture content of indoor surface, ventilation of case 2 has a significant effect in summer which reduces the moisture content from 0.0056 to $0.0043 \mathrm{~m}^{3} / \mathrm{m}^{3}$, but the moisture content in case 1 is similar with current state.

Reducing surface temperature and moisture content in summer benefits for avoiding mould growth, and it also can be helpful to less evaporation and salting-out. In winter, it is possible to use the control ventilation (Case 2 ) to decrease area of freezing, even though the surface temperature in case 2 is still below zero in figure 9(a). It may due to that the temperature control does not work all day, but only during the day.

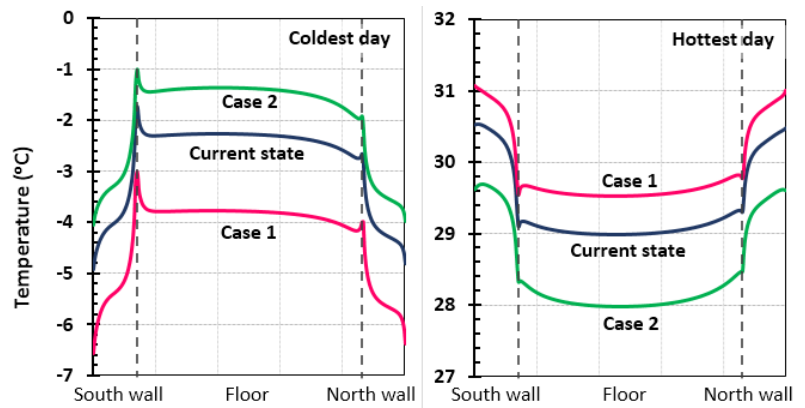

(a)

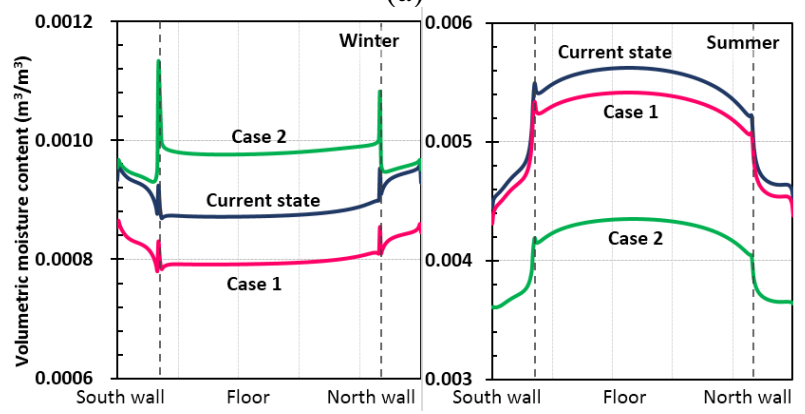

(b)

Fig. 9. Daily averaged indoor surface temperature and moisture content in winter and in summer before and after ventilation: (a) temperature $\left[{ }^{\circ} \mathrm{C}\right]$; (b) volumetric moisture content $\left[\mathrm{m}^{3} / \mathrm{m}^{3}\right]$. 


\subsection{Risk of mould growth after ventilation}

According to figure 9, indoor wall corners have the relatively high temperature and moisture content, and it is the fact that mould growth always occurs at corners in heritage buildings of the Palace Museum. Therefore, we choose Point-C 1 and Point-C 2 (figure 3) at corners of south wall and north wall respectively to show the mould growth risk in current state and two ventilation plans.

Figure 10 shows the results of mould risk from late March to early August with relative high indoor RH. The shaded area is the growth range (germination scope) of mould [3]. Daily averaged surface temperature and RH are applied in this analysis. If data points drop into the germination scope, it will be recorded as high risk day. Obviously, the situation of current state and case 1 are similar that there are $22 \sim 25$ days with high mould growth risk at the two corners. However, in case 2, high risk days decrease to 10 and 7 days at corners of south wall and north wall respectively. So control ventilation is effective to reduce mould growth risk on indoor surface.

Furthermore, comparing the data points of the three situation in figure 10, it can be found that $\mathrm{RH}$ is the main reason of moving out the risk scope in case 2, but the temperature of data points in the three situation do not change a lot. Consequently, the key point of the control ventilation plan is dehumidification.
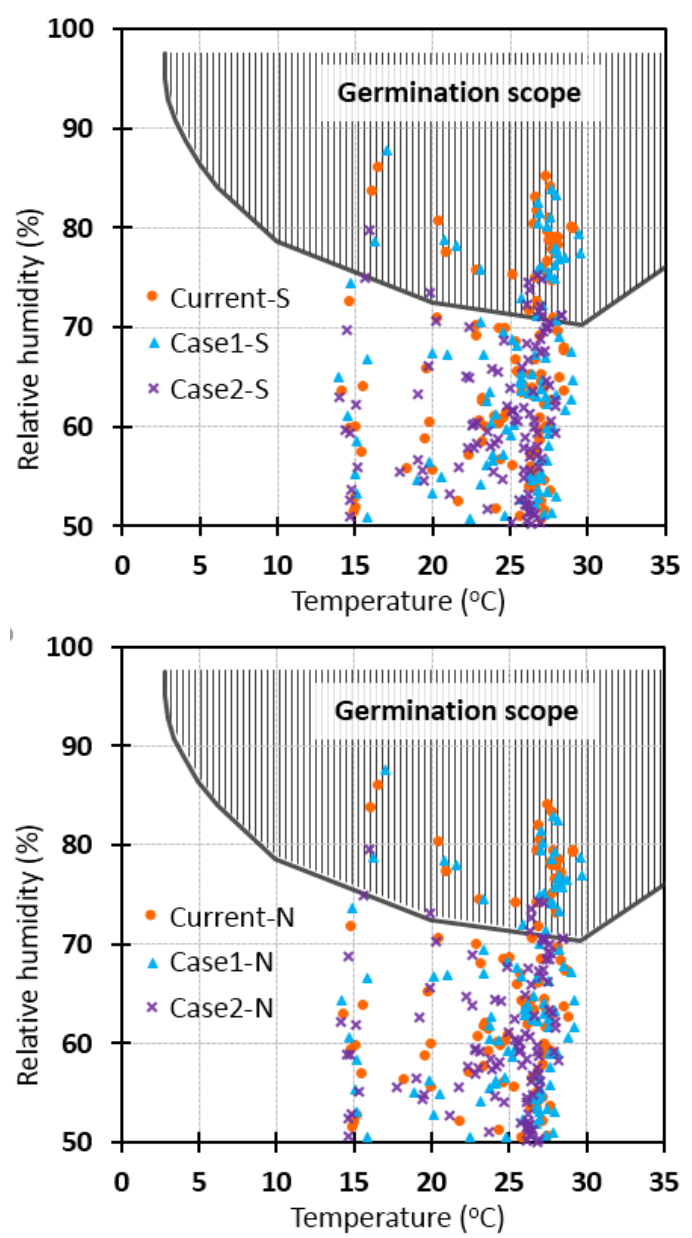

Fig. 10. Mould growth risk depending on surface temperature and RH at south wall corner and north wall corner. (S refers to south wall; $\mathrm{N}$ refers to north wall)

\section{Conclusion}

For the purpose of making clear the effects of ventilation through flue on reducing moisture damage in Tishun Tang, we firstly carried out the environment monitoring, and then we built a numerical model to simulate the hygrothermal performance of the building.

The monitoring of ground water content and indoor relative humidity shows that there is a low-permeability ground layer between two and three meters underground. That is the main reason of the shallow ground water forming at 2.3 meters underground, which directly leads to humid micro-environment near floor and wall bottom. Those characteristic of ground under the building should be took into account into the hygrothermal model.

Compared with way of outdoor air exchanging with indoor air directly through the flue, controlling the temperature and humidity of the air going indoors is more efficient. Heating the outdoor air before air exchange in winter helps to reduce the area of freezingthawing damage on indoor surface. Dehumidifying the outdoor air during ventilation is the most significant measure in summer to decrease mould risk on indoor surface.

Thanks to the Palace Museum for providing the study case for this paper. Thanks to the department of Architectural Heritage of the Palace Museum for their assistance in weather data, field survey and environment monitoring. This work was supported by The Palace Museum research project of Yangxin Dian (No. 201903042), and NSFC (No. 51878140).

\section{References}

1. L. Yonghui, H. Xie, J. Wang, X. Li, Experimental study of the isothermal sorption properties of late Qing and 1980s grey bricks in Wujiang, Suzhou, China, Front. Archit. Res. 2, 483-487 (2013) doi:10.1016/j.foar.2013.08.006.

2. Z. Kong, Y. Li, S. Hokoi, S. Hu, The rising damp in two traditional clay-brick masonry walls and influence on heat transfer performance, MATEC Web Conf. (2019). doi:10.1051/matecconf/201928202097.

3. K. Sedlbauer, Prediction of mould fungus formation on the surface of/and inside building components, Stuttgart University (2001) https://www.hoki.ibp.fraunhofer.de/ibp/publikation en/dissertationen/ks_dissertation_e.pdf.

4. Y. Shen, W. Chen, J. Kuang, W. Du, Effect of salts on earthen materials deterioration after humidity cycling, J. Cent. South Univ. 24 796-806 (2017) doi:10.1007/s11771-017-3482-0.

5. W. Araoka, S. Hokoi, D. Ogura, C. Iba, Y. Li, S. $\mathrm{Hu}$, Deterioration and Preservation of City Wall in Nanjing, Energy Procedia, 945-950 (2017) doi:10.1016/j.egypro.2017.09.734.

6. P. Li, J. Zhang, X. Zhang, The Positive and Negative Value Effect of Underground Kangs in Ancient Architectures: The History, Conservation and Reuse Strategies of Chinese Ancient Heating 
Facilities (in Chinese), Archit. J. S1 156-163 (2019)

7. M. Matsumoto, S. Hokoi, M. Hatano, Model for simulation of freezing and thawing processes in building materials, Build. Environ. 36, 733-742 (2001) doi:10.1016/S0360-1323(00)00066-4.

8. M. Radeka, J. Ranogajec, R. Marinkovic-Neducm, V. Ducman, A.S. Skapin, The effect of the firing temperature of clay roofing tiles on the mechanisms of frost action, Ind. Ceram. 30, 97-104 (2010)

9. E. Mizutani, D. Ogura, T. Ishizaki, M. Abuku, J. Sasaki, Degradation of the wall paintings of Hagia Sophia in Istanbul, (n.d.).

10. Y. Ma, Z. Kong, Y. Li, X. Zhang, S. Hokoi, X. Fu, Quantitative evaluation of deterioration in west wind-room in the Palace Museum, MATEC Web Conf. (2019). doi:10.1051/matecconf/201928202092.

11. X. Zhang, On Theoretical Guidelines of and Technical Approaches to the Research of the Surroundings of the Compound of the Hall of Mental Cultivation (Lun Yangxin dian qu jianzhu huanjing yanjiu de lilun yu jishu fangfa), J. Gugong Stud. (Gugong Xue Kan). 1 160-182 (2018) 